\title{
BMJ Open Metabolic syndrome and its components with neuron-specific enolase: a cross- sectional study in large health check-up population in China
}

Shu-Yi Wang, ${ }^{1}$ Xiao-Juan Zha, ${ }^{2}$ Xin-Ying Zhu, ${ }^{1}$ Wen-Bo Li, ${ }^{3}$ Jun Ma, ${ }^{1}$ Ze-Wei Wu, ${ }^{1}$ Huan Wu, ${ }^{1}$ Ming-Fei Jiang, ${ }^{1}$ Yu-Feng Wen ${ }^{1}$
To cite: Wang S-Y, Zha X-J, Zhu X-Y, et al. Metabolic syndrome and its components with neuron-specific enolase: a cross-sectional study in large health check-up population in China. BMJ Open 2018;8:e020899. doi:10.1136/ bmjopen-2017-020899

- Prepublication history for this paper is available online. To view these files, please visit the journal online (http://dx.doi. org/10.1136/bmjopen-2017020899).

Received 2 December 2017 Revised 25 February 2018 Accepted 15 March 2018

\section{Check for updates}

${ }^{1}$ School of Laboratory Medicine, Wannan Medical College, Wuhu, Anhui Province, China

${ }^{2}$ Medical Examination Center, The First Affiliated Hospital of Wannan Medical College, Yijishan Hospital, Wuhu, Anhui Province, China

${ }^{3}$ School of Clinical Medicine, Wannan Medical College, Wuhu, Anhui Province, China

Correspondence to Professor Yu-Feng Wen; wyf@wnmc.edu.cn

\section{ABSTRACT}

Objective This study was aimed at investigating the relationship between neuron-specific enolase (NSE) and components of metabolic syndrome (MS).

Design Cross-sectional study.

Setting Chinese health check-up population.

Participants 40684 health check-up people were enrolled in this study from year 2014 to 2016.

Main outcome measures OR and coefficient for MS. Results The percentage of abnormal NSE and MS was $26.85 \%$ and $8.85 \%$, respectively. There were significant differences in sex, body mass index, drinking habit, triglycerides (TGs), high-density lipoprotein cholesterol (HDL-C), blood pressure and MS between low-NSE and high-NSE groups. In logistic regression analysis, elevated NSE was present in MS, higher body mass index, hypertriglyceridaemia, hypertension and low-HDL groups. Stepwise linear analysis showed a negative correlation between NSE and fasting blood glucose (FBG) $(<6.0 \mathrm{mmol} / \mathrm{L})$, and a positive correlation between NSE and TGs (<20 mmol/L), systolic blood pressure $(75-200 \mathrm{~mm}$ $\mathrm{Hg})$, HDL-C (0.75-2.50 mmol/L), diastolic blood pressure $(<70 \mathrm{~mm} \mathrm{Hg})$ and FBG $(6.00-20.00 \mathrm{mmol} / \mathrm{L})$. Furthermore, MS was positively correlated with NSE within the range of $2.00-7.50 \mathrm{ng} / \mathrm{mL}$, but had a negative correlation with NSE within the range of $7.50-23.00 \mathrm{ng} / \mathrm{mL}$.

Conclusion There are associations between NSE with MS and its components. The result suggests that NSE may be a potential predictor of MS. Further research could be conducted in discussing the potential mechanism involved.

\section{INTRODUCTION}

Metabolic syndrome (MS) and its components are important factors in cerebrovascular diseases. The components of MS, such as overweight or obesity, hypertension, hyperlipidaemia and hyperglycaemia, are independently or jointly linked to the aetiology of atherosclerosis and stroke. ${ }^{1-7}$ It has been reported that the risks of atherosclerosis in MS population over 5-10 years were two times higher than those in non-MS population. ${ }^{8}$ People with MS have a higher prevalence of cerebral events, especially of non-fatal
Strengths and limitations of this study

- There is no study about the relationship between neuron-specific enolase (NSE) and metabolic syndrome (MS); this study based on a large sample of population revealed that NSE and MS may probably have a causal relationship.

- The health check-up population varies from the general population, so that the representativeness of this conclusion is limited.

- This cross-sectional study was carried out in one hospital that might not consider the population in other settings.

- Brain MRI was not performed to evaluate the degree of brain impairment; thus, the interpretation of the inherent association mechanism between NSE and MS is limited.

ischaemic stroke. ${ }^{9}$ This relationship has been confirmed by other studies. ${ }^{10-12}$

Neuron-specific enolase (NSE) is one of the isozymes of the enolase family. Two of the three subunits which constitute the enolase family form two types of dimers ( $\alpha \gamma$ and $\gamma \gamma$ ), which specifically exist in neurons. ${ }^{13}$ NSE is a tumour marker, especially in detecting small cell lung cancer. ${ }^{14}{ }^{15}$ In 1997 , Missler et al found a trend towards elevated levels of NSE in patients with stroke ${ }^{16}$; subsequently, number of studies revealed that serum NSE was elevated in patients with brain injury. ${ }^{17-20}$ It has been shown that NSE is more efficient when used in conjunction with other biomarkers in assessing the risk of cardiovascular disease and transient ischaemic attack. $^{21} 22$ Thus, NSE is also considered as a sensitive marker for evaluating the severity of craniocerebral injury and prognosis of relevant diseases. ${ }^{23}$

However, there are no reports on the association between NSE and MS, although. Studies have demonstrated the relationship 
of MS with brain dysfunction, and the association between blood pressure (BP), blood glucose and NSE. ${ }^{24-27}$ If a predictive relationship exists between NSE and MS or its components, it will be of immense value in early diagnosis of the impairment of brain function by MS.

This current investigation is a cross-sectional study on a large health check-up population with the aim of exploring the relationship between NSE and MS and its components.

\section{METHODS}

\section{Patients}

A health check-up population from the Physical Examination Center of the First Affiliated Hospital of Wannan Medical College, in Wuhu, China, was enrolled in this study from 2014 to 2016. Inclusion criteria: (1) age within the range 18-89 years; (2) evidence of having undergone tumour marker tests and (3) the absence of history of brain disease intervention. The exclusion criteria included: (1) the absence of available data on triglyceride (TG), fasting blood glucose (FBG), uric acid, high-density lipoprotein, blood urea nitrogen (BUN), glutamic-pyruvic transaminase, glutamic oxaloacetate, aminotransferase, NSE; (2) individuals with brain disease intervention, tumour or cancer, severe cardiovascular diseases or severe infections. A total of 40684 subjects consisting $25604(62.93 \%)$ men and 15080 $(37.07 \%)$ women were enrolled in this cross-sectional study. Their mean age was $50.49 \pm 13.52$ years. The study was conducted in compliance with Helsinki guidelines of the Helsinki Declaration of World Medical Association. Verbal informed consent was obtained from each participant before the investigation.

\section{Questionnaire survey}

A questionnaire was designed by clinical and epidemiological experts. It contained demographic and behavioural characteristics, history of diseases and operations, and body examinations. The demographic characteristics included sex, age, occupation, educational backgrounds, and so on. The behavioural characteristics included smoking (scored as $0=$ never smoking, $1=$ smoking occasionally and $2=$ smoking frequently) and drinking (scored as $0=$ never drinking, $1=$ drinking occasionally and $2=$ drinking frequently). The history of diseases and operations included the information of severe infections, cardiovascular diseases, major surgeries and tumour or cancer.

\section{Physical examination}

The physical examination included height, weight and BP. Subjects were assessed when barefooted by professional staff. They were required to have their eyes straight ahead and upper limbs put on both sides of the body in a natural pose; height data were acquired to the nearest $0.1 \mathrm{~cm}$. The subjects maintained steady body positions during the body weight measurement and wore minimal clothing. Weight data were acquired to the nearest $0.1 \mathrm{~kg}$. The body mass index (BMI) was calculated as: weight $(\mathrm{kg}) /$ square of height $\left(\mathrm{m}^{2}\right)$. The BMI data were calculated to the nearest $0.01 \mathrm{~kg} / \mathrm{m}^{2}$. BP was measured using a mercury sphygmomanometer, after the subjects rested for $5 \mathrm{~min}$. Systolic blood pressure (SBP) and diastolic blood pressure (DBP) were measured.

\section{Biochemical assays}

A total of $5 \mathrm{~mL}$ venous blood from each subject was used for the measurement of biochemical indices. The specimens were collected from the participants after 12-hour fast and then centrifuged and stored at $-70 \square$ until assayed. All specimens were assayed within 24 hours. The parameters assayed were TG, FBG, high-density lipoprotein cholesterol (HDL-C), BUN and NSE. The measurement of NSE concentrations was done with commercial ELISA kits (CanAg NSE EIA, Göteborg, Sweden). All biochemical assays were performed by laboratory technicians in the hospital.

\section{Classification of participants/definitions}

All participants were divided into subgroups according to BMI $\left(\geq 25 \mathrm{~kg} / \mathrm{m}^{2}\right.$ group and $<25 \mathrm{~kg} / \mathrm{m}^{2}$ group) and NSE $\left(\geq 12.5 \mathrm{ng} / \mathrm{mL}\right.$ group and $<12.5 \mathrm{ng} / \mathrm{mL}$ group) ${ }^{28}$ Hypertension was defined as SBP $\geq 140 \mathrm{~mm} \mathrm{Hg}$ and/ or DBP $\geq 90 \mathrm{~mm} \mathrm{Hg}$ or under treatment with antihypertensive drugs. Hyperglycaemia was defined as FBG $\geq 6.1 \mathrm{mmol} / \mathrm{L}$. Hypertriglyceridaemia was defined as $\mathrm{TG} \geq 1.7 \mathrm{mmol} / \mathrm{L}$. Low high-density lipoprotein referred to HDL-C $<0.9 \mathrm{mmol} / \mathrm{L}$ in men, and HDL-C $<1.0 \mathrm{mmol} / \mathrm{L}$ in women, while MS was defined according to the Chinese Diabetes Society (CDS) criteria. ${ }^{29}$

\section{Statistical analysis}

Characteristics of the population were illustrated by simple descriptive statistics; the data were expressed as mean $\pm \mathrm{SD}$ for continuous variables or frequency $(\%)$ for categorical variables. The comparison of demographic characteristics and biochemical indices between $\geq 12.5 \mathrm{ng} / \mathrm{mL}$ and $<12.5 \mathrm{ng} / \mathrm{mL}$ groups was done using $\chi^{2}$ test. Then, multivariable logistic regression model analysis was used to explore the relationship between MS and its components with NSE, and adjusted for possible confounding factors such as sex, age, drinking and BUN, to provide the OR and $95 \%$ CI values. Stepwise correlation analysis was used to explore the correlation between the components of MS and NSE. Before and after adjustment for sex, age, drinking and BUN, R package with mgcv and ggplot V.2.0 was used to explore the generalised smoothing splines between NSE and MS components. Linear regression was conducted to estimate the relationship between NSE and MS components with or without adjustment for potential confounders. Participants were divided into four groups by quartiles $\left(<\mathrm{P}_{25}, \mathrm{P}_{25}-\mathrm{P}_{50}, \mathrm{P}_{50}-\mathrm{P}_{75}\right.$ and $\left.\geq \mathrm{P}_{75}\right)$ of NSE in each segment, and stepwise logistic regression was conducted to test the connection between NSE and MS. All tests were two-sided and statistical significance level was considered 
as ' $\alpha=0.05$ '. Data management and all analyses were performed using R software program (V.3.0.0).

\section{Patient and public involvement}

No patients were involved in developing the questionnaire, the hypothesis and plans or implementation for this study. No patients were involved in the data analysis or the manuscript writing. And we did not plan to disseminate the results of this study to participants or some relevant people.

\section{RESULTS \\ Demographic characteristics and biochemical indices between NSE}

The demographic characteristics and biochemical indices of the NSE subgroups are shown in table 1. The results show that $26.87 \%$ of the population had abnormal NSE level, and the prevalence of MS was $8.85 \%$. In the MS group, NSE concentration was $9.47 \pm 6.07 \mathrm{ng} / \mathrm{mL}$, and in non-MS group, the concentration was $9.06 \pm 5.83 \mathrm{ng} / \mathrm{mL}$. There were significant differences in BMI, TG, HDL-C and BP between the two NSE groups. In addition, the two NSE groups differed significantly with respect to other baseline characteristics such as sex, drinking habit and BUN.

\section{Relationship between components of MS and NSE}

Variables which had significant differences in the two NSE groups were adjusted. Based on multiple logistic regression analysis, elevated NSE level was found in MS individuals. In stepwise linear analysis of the relationship between MS components and NSE, a positive relationship was found in BMI $(\beta=0.0627, p<0.0001)$, TG $(<20 \mathrm{mmol} / \mathrm{L}, \beta=0.2553, \mathrm{p}<0.0001)$, SBP $(75-200 \mathrm{~mm} \mathrm{Hg}$, $\beta=0.0487, \quad p<0.0001)$, DBP $(<70 \mathrm{~mm} \mathrm{Hg}, \beta=0.01846$, $\mathrm{p}<0.0001 ; \geq 70 \mathrm{~mm} \mathrm{Hg}, \quad \beta=0.0156, \mathrm{p}<0.0001)$, HDL-C $(0.75-1.25 \mathrm{mmol} / \mathrm{L}, \beta=8.4354, \mathrm{p}<0.0001)$ and FBG $(6.00$ $20.0 \mathrm{mmol} / \mathrm{L}, \beta=0.041, \mathrm{p}=0.0353)$. However, a negative relationship was found in FBG $(<6.00 \mathrm{mmol} / \mathrm{L}, \beta=-0.599$, $\mathrm{p}<0.0001)$. These results are shown in table 2 and in figures 1 and 2.

After adjusting potential risk factors, the relationship between NSE and MS changed as a function of NSE concentration. Results from stepwise regression analysis revealed that $\mathrm{OR}<1$ when NSE concentration ranges from $2.00 \mathrm{ng} / \mathrm{mL}$ to $7.50 \mathrm{ng} / \mathrm{mL}$, indicating that NSE was negatively related to MS in this range. And OR $>1$ when NSE concentration ranges from $7.50 \mathrm{ng} / \mathrm{mL}$ to $23.00 \mathrm{ng} / \mathrm{mL}$, indicating that NSE was positively related to MS (figures 3 and 4).

\section{DISCUSSION}

The findings of this research show differences in NSE concentration between MS and non-MS population. Moreover, there were correlations between MS components and NSE. The effect of MS on brain can be reflected by changes in the concentration of NSE. In the absence of serious lesion, NSE is retained in the nerve cell because there is no cellular damage. Thus, NSE would not be detectable in peripheral blood. ${ }^{30}$ Therefore, NSE and MS components showed a certain association only in a limited range.

After adjusting a number of factors, there was weak correlation between BMI and NSE. In a previous study, Samanc et al reported that there was no correlation between BMI and NSE. ${ }^{25}$ The difference between their findings and the findings in the present study might be partly ascribed to differences in sample size. In addition, the mean age of people enrolled in this study was $50.49 \pm 13.52$ years, while in the study by Samanc et al, the mean ages of idiopathic intracranial hypertension and control groups were $35.40 \pm 9.85$ and $37.10 \pm 9.65$ years, respectively.

In this study, NSE was positively associated with risk of elevated TG. This is in agreement with the findings of Lindenstrom et al who reported that plasma TG was positively associated with ischaemic stroke. ${ }^{31}$ Similar results were obtained by other workers. ${ }^{32}{ }^{33}$ However, there are some reports indicating no association between NSE and TGs at all. ${ }^{34}$ Thus, from the viewpoint of previous research, the correlation between TG and stroke or ischaemic stroke was controversial, partly due to differences in blood samples used, some collected the non-fasting blood samples, ${ }^{30} 32$ while others used fasting blood samples. ${ }^{34} 35$ In the present research, TG levels were assessed on fasting blood samples, and serum NSE level was measured to evaluate brain injury. Elevated serum NSE has been shown to be related to the volume of brain infarction tissue. ${ }^{36}$ Differences in the degrees of stroke impairment might be responsible for the disparities in the results from different studies. In addition, the criteria of abnormal TG used also varied. Therefore, more precise and rigorous investigations are required.

HDL-C showed a positive association with NSE at a range of $0.75-2.50 \mathrm{mmol} / \mathrm{L}$, which indicated that HDL-C was positively associated with NSE in the normal range of HDL-C. Serum NSE levels could reflect impairment due to cerebral infarction. ${ }^{20}$ This finding is inconsistent with the popular view that HDL-C level is a protective factor against stoke. ${ }^{37}$ Indeed, it has been found that HDL-C is related to an increased risk factor of stroke in women. ${ }^{38}$ However, in this study, the number of female participants was smaller than the number of males enrolled. This association between NSE and HDL-C has not been reported before. Several aspects of this phenomenon should be considered. Maybe in the other studies, emphasis was on the stoke events, while in the present study, NSE was used as a marker of brain damage (including stroke and other brain diseases). Some unknown mechanism may exist, which need to be discussed in the future. Another possible explanation could be that the relationship between cardiovascular disease and HDL-C affects the association between cerebrovascular diseases. ${ }^{38}$ 
Table 1 Comparison of the demographic characteristics and biochemical indices between NSE subgroups

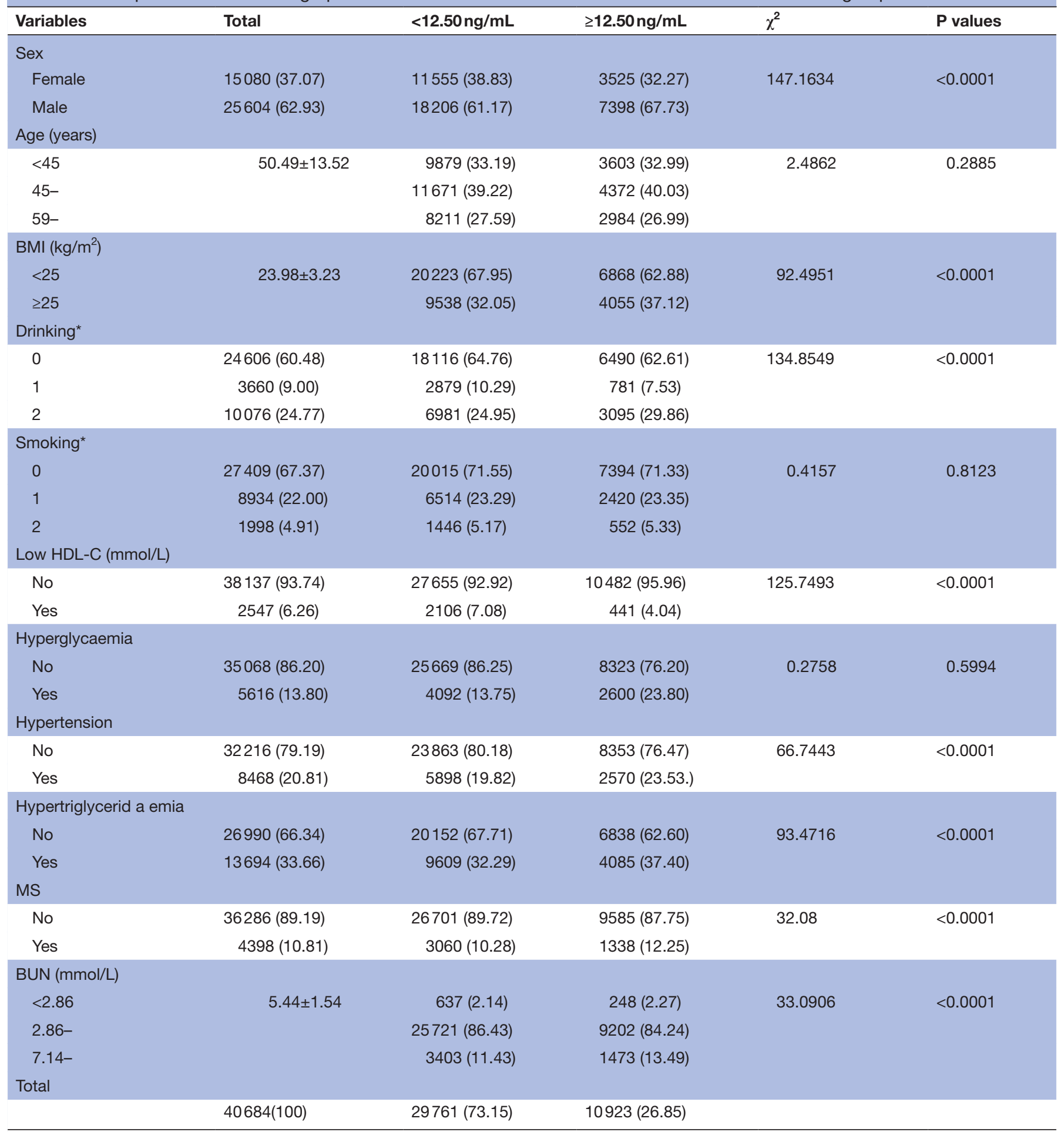

*For drinking, $0=$ never drink, $1=$ drink occasionally,and 2=drink frequently; for smoking, $0=$ neversmoke, $1=$ smoke occasionally and $2=$ smoke frequently. The figures in brackets are percentages.

BMI, body mass index; BUN, blood urea nitrogen; HDL-C, high-density lipoprotein cholesterol; MS, metabolic syndrome.

Hypertension is associated with cerebrovascular diseases; patients who had hypertension were more susceptible to cerebrovascular diseases. ${ }^{39-41}$ In this study, there was a positive correlation between SBP/DBP and NSE, when SBP ranges from $75 \mathrm{~mm} \mathrm{Hg}$ to $200 \mathrm{~mm} \mathrm{Hg}$, and $\mathrm{DBP}<70 \mathrm{~mm} \mathrm{Hg}$, which is in agreement with the results of González-Quevedo $e t a l^{2742}$ had done. In addition, a study on the Atherosclerosis Risk in Communities found that high BP was the most important risk factor for all subtypes of stroke. It was explained that hypertension was associated with white matter lesions, which caused elevations in NSE levels. ${ }^{2742}$ However, the authors of 
Table 2 Stepwise linear regression model of the relationship between metabolic syndrome (MS) components and neuronspecific enolase

\begin{tabular}{|c|c|c|c|c|c|c|c|}
\hline \multirow[b]{2}{*}{ MS components } & & \multicolumn{3}{|c|}{ Unadjusted } & \multicolumn{3}{|c|}{ Adjusted* } \\
\hline & & $\beta$ & SE & $P$ values & $\boldsymbol{\beta}$ & SE & P values \\
\hline \multirow[t]{2}{*}{ BMI $\left(\mathrm{kg} / \mathrm{m}^{2}\right)$} & $<25$ & 0.1057 & 0.0188 & $<0.0001$ & 0.0627 & 0.0098 & $<0.0001$ \\
\hline & $\geq 25$ & 0.0077 & 0.0257 & 0.7639 & & & \\
\hline $\mathrm{TG}(\mathrm{mmol} / \mathrm{L})$ & $<20$ & 0.3018 & 0.0224 & $<0.0001$ & 0.2553 & 0.0237 & $<0.0001$ \\
\hline $\mathrm{SBP}(\mathrm{mm} \mathrm{Hg})$ & $75-200$ & 0.0417 & 0.0017 & $<0.0001$ & 0.0487 & 0.0019 & $<0.0001$ \\
\hline \multirow[t]{2}{*}{ DBP (mm Hg) } & $<80$ & 0.0887 & 0.0083 & $<0.0001$ & 0.0294 & 0.6063 & $<0.0001$ \\
\hline & $\geq 80$ & 0.0324 & 0.0062 & $<0.0001$ & 0.0734 & 0.0085 & $<0.0001$ \\
\hline \multirow[t]{2}{*}{ HDL-C (mmol/L) } & $0.75-$ & 7.5522 & 0.3982 & $<0.0001$ & 8.4354 & 0.4096 & $<0.0001$ \\
\hline & $1.25-2.50$ & -0.2347 & 0.1393 & 0.0919 & 0.1196 & 0.1455 & 0.4111 \\
\hline \multirow[t]{2}{*}{ FBG (mmol/L) } & $<6.00$ & -0.5329 & 0.0704 & $<0.0001$ & -0.599 & 0.074 & $<0.0001$ \\
\hline & $6.00-20.00$ & 0.1043 & 0.0388 & 0.0072 & 0.0937 & 0.0403 & 0.0202 \\
\hline
\end{tabular}

${ }^{*}$ Adjusted for sex, age, drink and blood urea nitrogen.

$\beta$ stands for coefficient. BMI, body mass index; DBP, diastolic blood pressure; FBG, fasting blood glucose; HDL-C, high-density lipoprotein cholesterol; SBP, systolic blood pressure; TG, triglyceride.

the present study consider that hypertension might do harm to grey matter of the brain which is composed of a large number of neurons, and this damage might be reflected by changes in NSE. ${ }^{44}$ Since image inspection was not performed in this study, further imaging examination is required to identify this damage. The underlying mechanism remains to be studied. In other subgroups of SBP and DBP, the correlation was not valid because of the lack of adequate population.

FBG had a negative association with $\mathrm{NSE}<6.0 \mathrm{mmol} / \mathrm{L}$. Low FBG leads to hypoglycaemia. Hypoglycaemia damages the brain because brain activity relies on the circulating glucose as its main energy source. ${ }^{45} 46$ Thus, NSE decreased with increasing FBG $(\mathrm{FBG}<6.0 \mathrm{mmol} / \mathrm{L})$ in contrast to the positive association for $\mathrm{FBG}>6.0 \mathrm{mmol} / \mathrm{L}$. It is well known that elevated FBG is one of the risk factors for cerebrovascular diseases. ${ }^{47}$ This is consistent with the results of the current study. The only difference was that different correlations were obtained for subgroups of FBG.

From the analyses results, there were links between NSE and each component of MS. Figures 2 and 4 show that there might exist a connection between NSE and MS. When NSE concentration ranges from $2.00 \mathrm{ng} / \mathrm{mL}$ to

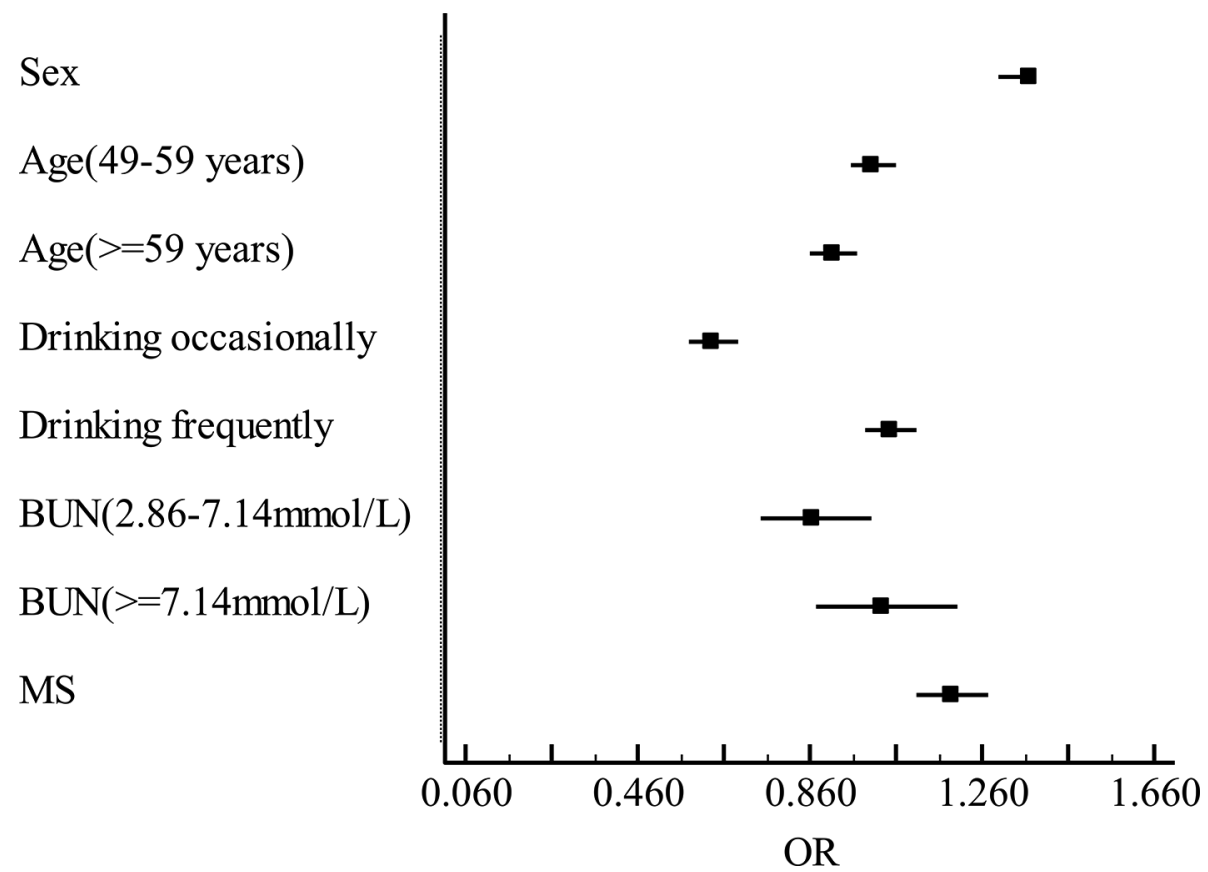

Figure 1 Multiple logistic regression analysis of the factors that influence neuron-specific enolase (NSE). Adjusted for sex, age, drink and blood urea nitrogen (BUN), the dependent variable was NSE, while the independent variable was metabolic syndrome (MS). The longitudinal coordinate represents potential factors that influence NSE, while the horizontal coordinate are ORs of NSE. 

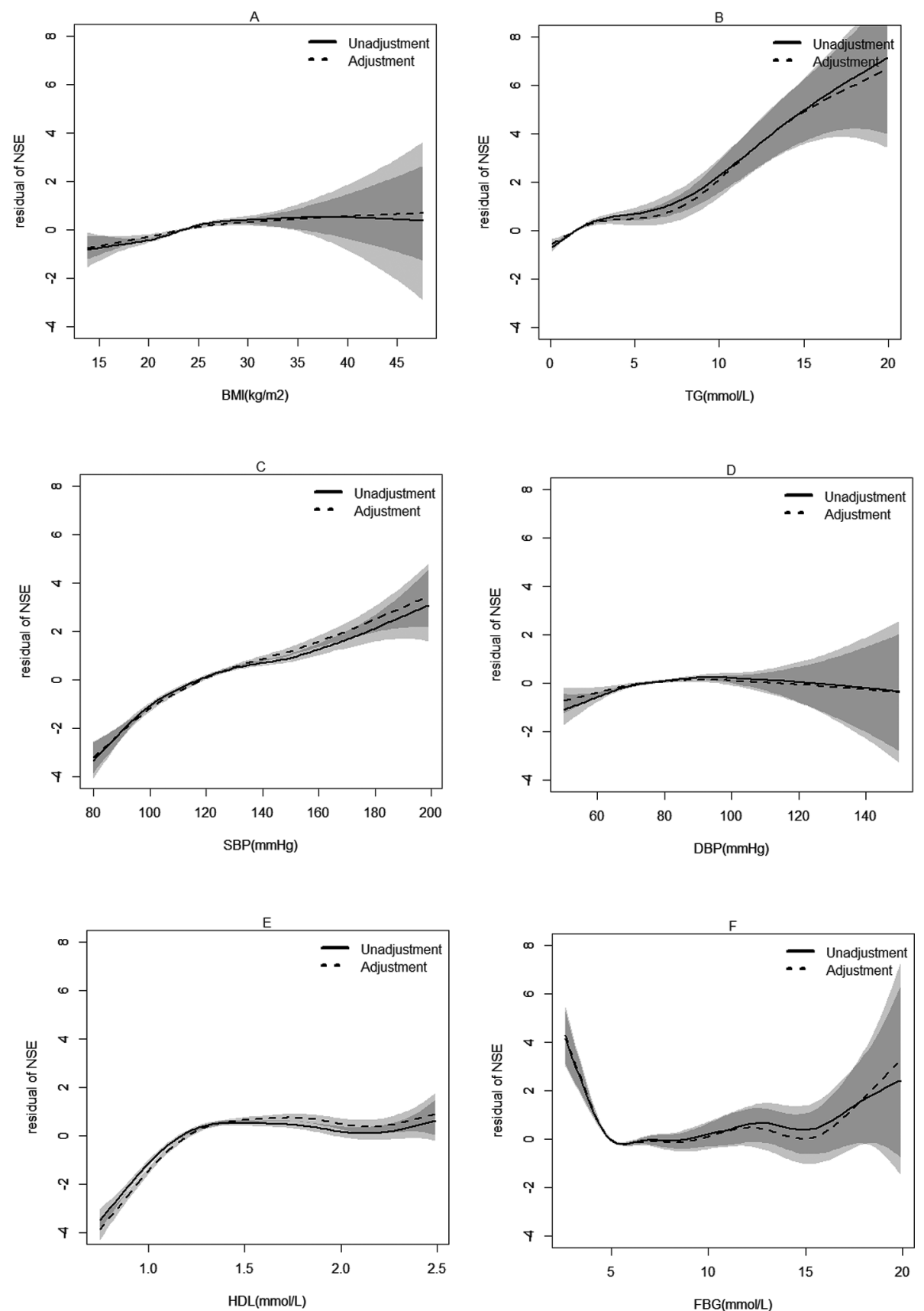

Figure 2 Stepwise correlation analysis of neuron-specific enolase (NSE) and metabolic syndrome (MS) components. The horizontal coordinate represents different components of MS; the longitudinal coordinate shows residual of NSE. Solid line: without adjustment; dotted line: adjustment for sex, age, drink and blood urea nitrogen. (A) Correlation of body mass index (BMI) with NSE. (B) Correlation of triglyceride (TG) with NSE. (C) Correlation of systolic blood pressure (SBP) with NSE. (D) Correlation of diastolic blood pressure (DBP) with NSE. (E) Correlation of high-density lipoprotein cholesterol (HDL-C) with NSE. (F) Correlation of fasting blood glucose (FBG) with NSE.

$7.50 \mathrm{ng} / \mathrm{mL}$, NSE levels showed negative correlation with MS. A positive correlation was found between NSE and MS when NSE concentration ranges from $7.50 \mathrm{ng} / \mathrm{mL}$ to $23.0 \mathrm{ng} / \mathrm{mL}$. It might mean that that NSE has nutritional function in the brain at low concentrations. Thus, it can protect brain tissue at a certain concentration. ${ }^{48}$ However, at a comparatively high level, NSE can reflect impairment of brain tissue. ${ }^{15}$ Therefore, NSE concentration may be a potential predictor in the course of occurrences and development of MS. Cerebral vascular stenosis or infarction results in insufficient blood supply to the brain, leading to the functional injury of brain, and NSE can reflect the degree of brain injury. ${ }^{49}$ The improvements in living standards have led to the rising incidence of MS. To some extent, the assay of NSE concentrations could predict a pathway for cardiovascular disease in MS populations. The advantage of the present study is that it is an epidemiological investigation based on a large sample size. This is essential for the validity and reliability of the results obtained. 


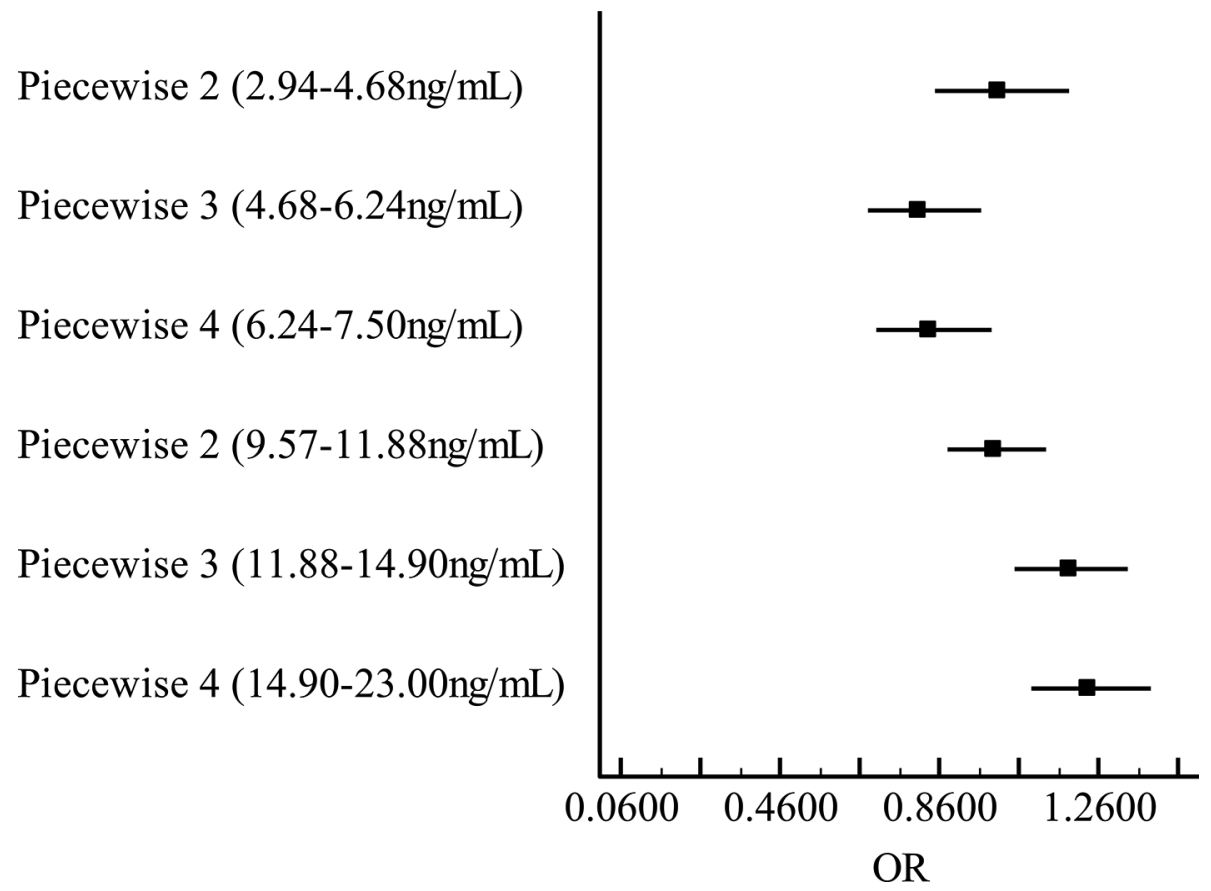

Figure 3 Stepwise logistic regression analysis between neuron-specific enolase (NSE) and metabolic syndrome (MS). Adjusted for sex, age and smoke. The longitudinal coordinate represents quartile segments of NSE; the horizontal coordinate is OR of MS.

\section{LIMITATIONS}

This is a cross-sectional study based on a large sample health check-up population, which varies from the general population. Thus, the representativeness of this conclusion is limited. In addition, the mechanism involved in the link between NSE and MS is still unclear. However, it is clear from this study that they probably have a causal relationship. In this study, NSE was not

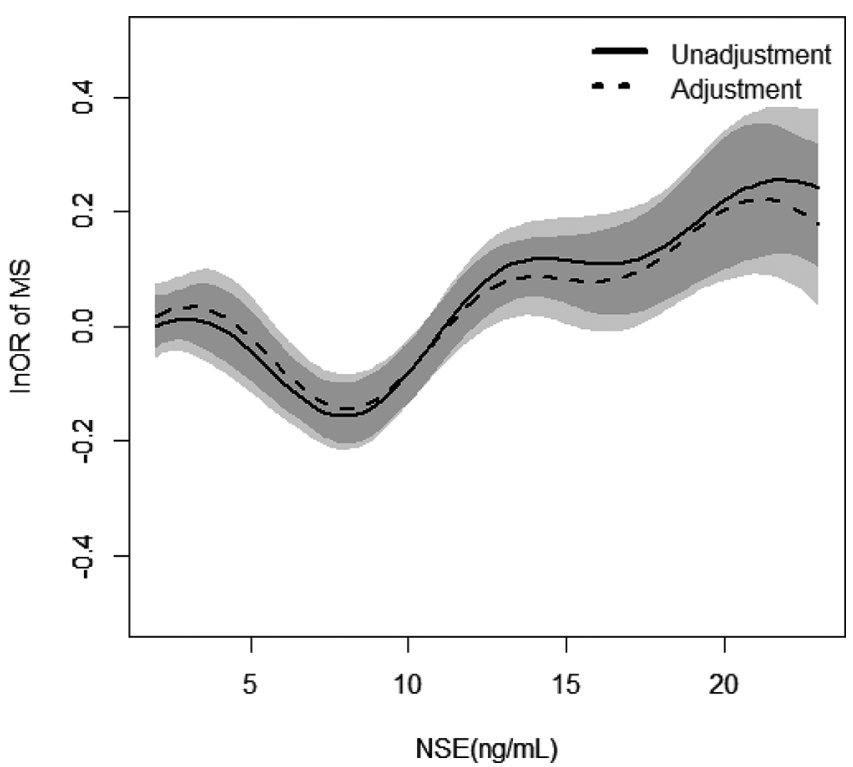

Figure 4 Relationship between neuron-specific enolase (NSE) and metabolic syndrome (MS) and their 95\% Cls (shade scope). The horizontal coordinate represents NSE; the longitudinal coordinate is InOR. Solid line: without adjustment; dotted line: adjustment for sex, age, drink and blood urea nitrogen. evaluated specifically for brain function. Moreover, MRI was not applied to evaluate the degree of impairment of brain due to financial constraints. This will be done in subsequent studies.

Acknowledgements We thank Wannan Medical College and the First Affiliated Hospital of Wannan Medical College for their help in this paper.

Contributors The project was designed by Y-FW and S-YW; data were collected by X-JZ, X-YZ and W-BL. JM, M-FJ, Z-WW and HW took part in the data entry and arrangement. Y-FW helped in data analysis. All authors contributed to the research and have read and approved the final manuscript.

Funding This research received no specific grant from any funding agency in the public, commercial or not-for-profit sectors.

Competing interests None declared.

Patient consent Obtained.

Ethics approval This study was approved by the Ethics Committee of Wannan Medical College.

Provenance and peer review Not commissioned; externally peer reviewed. Data sharing statement № additional unpublished data are available.

Open Access This is an Open Access article distributed in accordance with the Creative Commons Attribution Non Commercial (CC BY-NC 4.0) license, which permits others to distribute, remix, adapt, build upon this work non-commercially, and license their derivative works on different terms, provided the original work is properly cited and the use is non-commercial. See: http://creativecommons.org/ licenses/by-nc/4.0/

(c) Article author(s) (or their employer(s) unless otherwise stated in the text of the article) 2018. All rights reserved. No commercial use is permitted unless otherwise expressly granted.

\section{REFERENCES}

1. Karcher HS, Holzwarth R, Mueller HP, et al. Body fat distribution as a risk factor for cerebrovascular disease: an MRI-based body fat quantification study. Cerebrovasc Dis 2013;35:341-8. 
2. Ridker PM. Fasting versus nonfasting triglycerides and the prediction of cardiovascular risk: do we need to revisit the oral triglyceride tolerance test? Clin Chem 2008;54:11-13.

3. Boden WE. High-density lipoprotein cholesterol as an independent risk factor in cardiovascular disease: assessing the data from Framingham to the Veterans Affairs High-Density Lipoprotein Intervention Trial. Am J Cardiol 2000;86-19-22.

4. Long AN, Dagogo-Jack S. Comorbidities of diabetes and hypertension: mechanisms and approach to target organ protection. $J$ Clin Hypertens 2011;13:244-51.

5. Forouzanfar MH, Alexander L, Anderson HR, et al. Global, regional, and national comparative risk assessment of 79 behavioural, environmental and occupational, and metabolic risks or clusters of risks in 188 countries, 1990-2013: a systematic analysis for the Global Burden of Disease Study 2013. Lancet 2015;386:2287-323.

6. Dejong RN. The nervous system complications of diabetes mellitus, with special reference to cerebrovascular changes. J Nerv Ment Dis 1950;111:181-206.

7. Hanyu H. [Diabetes mellitus and dementia]. Brain Nerve 2014;66:129-34.

8. Chen J, Guo-Hou HE, Shao-Zu YU. The clinical significance of neuron-specific enolasein serially determinated on the patients with acute cerebral infarction. Journal of Apoplexy \& Nervous Diseases 2005;22:70-2.

9. Novo S, Peritore A, Guarneri FP, et al. Metabolic syndrome (MetS) predicts cardio and cerebrovascular events in a twenty years followup. A prospective study. Atherosclerosis 2012;223:468-72.

10. Ohta $\mathrm{Y}$, Takao $\mathrm{Y}, \mathrm{Harada} \mathrm{K}$, et al. Metabolic syndrome is a risk factor for acute cerebral infarction in a younger elderly Kurashiki population. J Stroke Cerebrovasc Dis 2012;21:231-9.

11. Kawamoto R, Tomita H, Oka Y, et al. Metabolic syndrome as a predictor of ischemic stroke in elderly persons. Intern Med 2005;44:922-7.

12. McNeill AM, Rosamond WD, Girman CJ, et al. The metabolic syndrome and 11-year risk of incident cardiovascular disease in the atherosclerosis risk in communities study. Diabetes Care 2005;28:385-90.

13. Orlino EN, Olmstead CE, Lazareff JA, et al. An enzyme immunoassay for neuron-specific enolase in cerebrospinal fluid. Biochem Mol Med 1997;61:41-6.

14. Ono A, Naito T, Ito I, et al. Correlations between serial pro-gastrinreleasing peptide and neuron-specific enolase levels, and the radiological response to treatment and survival of patients with small-cell lung cancer. Lung Cancer 2012;76:439-44.

15. Zhao WX, Luo JF. Serum neuron-specific enolase levels were associated with the prognosis of small cell lung cancer: a metaanalysis: Centre for Reviews and Dissemination (UK). 2013.

16. Missler U, Wiesmann M, Friedrich C, et al. S-100 Protein and neuron-specific enolase concentrations in blood as indicators of infarction volume and prognosis in acute ischemic stroke. Stroke 1997:28:1956-60.

17. Pinelis VG, Sorokina EG, Semenova JB, et al. Biomarkers in children with traumatic brain injury. Zhurnal nevrologii i psikhiatrii im. S.S. Korsakova 2015;115:66-72.

18. Krohn M, Dreßler J, Bauer M, et al. Immunohistochemical Investigation of S100 and NSE in Cases of Traumatic Brain Injury and Its Application for Survival Time Determination. J Neurotrauma 2015;32:430-40.

19. Hajduková L, Sobek O, Prchalová D, et al. Biomarkers of Brain Damage: S100B and NSE Concentrations in Cerebrospinal Fluid-A Normative Study. Biomed Res Int 2015;2015:1-7.

20. Gelderblom M, Daehn T, Schattling B, et al. Plasma levels of neuron specific enolase quantify the extent of neuronal injury in murine models of ischemic stroke and multiple sclerosis. Neurobiol Dis 2013;59:177-82.

21. Sharain K, Hoppensteadt D, Bansal V, et al. Progressive Increase of Inflammatory Biomarkers in Chronic Kidney Disease and EndStage Renal Disease. Clinical and Applied Thrombosis/Hemostasis 2013;19:303-8

22. Purroy F, Suárez-Luis I, Cambray S, et al. The determination of copeptin levels helps management decisions among transient ischaemic attack patients. Acta Neurol Scand 2016;134:140-7.

23. Brandner S, Thaler C, Buchfelder M, et al. Brain-derived protein concentrations in the cerebrospinal fluid: contribution of trauma resulting from ventricular drain Insertion. J Neurotrauma 2013;30:1205-10.

24. Singh RB, Gupta S, Dherange P, et al. Metabolic syndrome: a brain disease. Can J Physiol Pharmacol 2012;90:1171-83.
25. Samancı Y, Samancı B, Şahin E, et al. Neuron-specific enolase levels as a marker for possible neuronal damage in idiopathic intracranial hypertension. Acta Neurol Belg 2017;117:707-11.

26. Li J, Yan M, Zhang Y, et al. Serum neuron-specific enolase is elevated as a novel indicator of diabetic retinopathy including macular oedema. Diabetic Medicine 2015;32:102-7.

27. González-Quevedo A, García SG, Concepción OF, et al. Increased serum S-100B and neuron specific enolase - Potential markers of early nervous system involvement in essential hypertension. Clin Biochem 2011;44:154-9.

28. Fizazi K, Cojean I, Pignon JP, et al. Normal serum neuron specific enolase (NSE) value after the first cycle of chemotherapy: an early predictor of complete response and survival in patients with small cell lung carcinoma. Cancer 1998;82:1049-55.

29. Yh L, Jm L, Wang SY, et al. Comparison of the diagnostic criteria of metabolic syndrome by International Diabetes Federation and that by Chinese Medical Association Diabetes Branch]. Zhonghua yi xue za zhi 2006;86:386-9.

30. Haque A, Ray SK, Cox A, et al. Neuron specific enolase: a promising therapeutic target in acute spinal cord injury. Metab Brain Dis 2016:31:487-95.

31. Lindenstrom E, Boysen G, Nyboe J. Influence of total cholesterol, high density lipoprotein cholesterol, and triglycerides on risk of cerebrovascular disease: the Copenhagen city heart study. BMJ 1994;309:11-15.

32. Hachinski V, Graffagnino C, Beaudry M, et al. Lipids and stroke: a paradox resolved. Archives of Neurology 1996;53:303-8.

33. Freiberg JJ, et al. Nonfasting triglycerides and risk of ischemic stroke in the general population. JAMA 2008;300:2142-52.

34. Shahar E, Chambless LE, Rosamond WD, et al. Plasma lipid profile and incident ischemic stroke: the Atherosclerosis Risk in Communities (ARIC) Study. Stroke 2003;34:623-31.

35. Willey JZ, Qiang X, Bodenalbala B, et al. Lipid profile components and risk of ischemic stroke: the Northern Manhattan Study (NOMAS). Archives of Neurology 2009;66:1400-6.

36. Dong L, Hou R, Xu Y, et al. Analyzing the correlation between the level of serum markers and ischemic cerebral vascular disease by multiple parameters. Comput Math Methods Med 2015;2015:1-5.

37. Amarenco P, Labreuche J, Touboul P-J. High-density lipoproteincholesterol and risk of stroke and carotid atherosclerosis: A systematic review. Atherosclerosis 2008;196:489-96.

38. Bots ML, Elwood PC, Nikitin Y, et al. Total and HDL cholesterol and risk of stroke. EUROSTROKE: a collaborative study among research centres in Europe. Journal of Epidemiology \& Community Health 2002;56:i19-i24.

39. Henskens LH, van Oostenbrugge RJ, Kroon AA, et al. Detection of silent cerebrovascular disease refines risk stratification of hypertensive patients. J Hypertens 2009;27:846-53.

40. Chobanian AV, Bakris GL, Black HR, et al. Seventh report of the joint national committee on prevention, detection, evaluation, and treatment of high blood pressure. Hypertension 2003;42:1206-52.

41. Maillard P, Seshadri S, Beiser A, et al. Effects of systolic blood pressure on white-matter integrity in young adults in the Framingham Heart Study: a cross-sectional study. Lancet Neurol 2012;11:1039-47.

42. González-Quevedo A, González-García S, Hernández-Díaz Z, et al. Serum neuron specific enolase could predict subclinical brain damage and the subsequent occurrence of brain related vascular events during follow up in essential hypertension. J Neurol Sci 2016;363:158-63.

43. Avet $\mathrm{J}$, Pichot $\mathrm{V}$, Barthélémy $\mathrm{J}-\mathrm{C}$, et al. Leukoaraiosis and ambulatory blood pressure load in a healthy elderly cohort study: The PROOF study. Int J Cardiol 2014;172:59-63.

44. Kharabian Masouleh S, Beyer F, Lampe L, et al. Gray matter structural networks are associated with cardiovascular risk factors in healthy older adults. J Cereb Blood Flow Metab 2018;38:17.

45. Auer RN, Wieloch T, Olsson Y, et al. The distribution of hypoglycemic brain damage. Acta Neuropathol 1984;64:177-91.

46. Auer RN. Progress review: hypoglycemic brain damage. Stroke 1986;17:699-708.

47. Ergul A, Kelly-Cobbs A, Abdalla M, et al. Cerebrovascular complications of diabetes: focus on stroke. Endocr Metab Immune Disord Drug Targets 2012;12:148-58.

48. Hattori T, Takei N, Mizuno Y, et al. Neurotrophic and neuroprotective effects of neuron-specific enolase on cultured neurons from embryonic rat brain. Neurosci Res 1995;21:191-8.

49. Gutierrez J, Elkind MSV, Virmani R, et al. A pathological perspective on the natural history of cerebral atherosclerosis. Inter J Stroke 2015;10:1074-80. 